Témoigner Témoigner. Entre histoire et mémoire

Getuigen Revue pluridisciplinaire de la Fondation Auschwitz

127 | 2018

Perpétuation de la violence après 1918

\title{
Het memoriaal van Neugengamme
}

Le KL Neuengamme

Johan Puttemans

\section{(2) OpenEdition}

Journals

Édition électronique

URL : https://journals.openedition.org/temoigner/7771

DOI : 10.4000/temoigner.7771

ISSN : 2506-6390

Cet article est une traduction de :

Le KL Neuengamme - URL : https://journals.openedition.org/temoigner/7766 [fr]

Éditeur :

Éditions du Centre d'études et de documentation Mémoire d'Auschwitz, Éditions Kimé

Édition imprimée

Date de publication : 1 octobre 2018

Pagination : $20-29$

ISBN : 978-2-930953-076

ISSN : 2037-4183

Référence électronique

Johan Puttemans, «Het memoriaal van Neugengamme», Témoigner. Entre histoire et mémoire [Online], 127 | 2018, Online op 10 février 2022, geraadpleegd op 14 février 2022. URL: http:// journals.openedition.org/temoigner/7771 ; DOI: https://doi.org/10.4000/temoigner.7771 




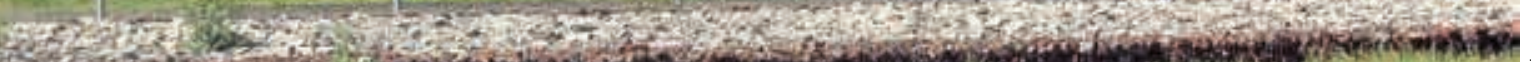
A.7.

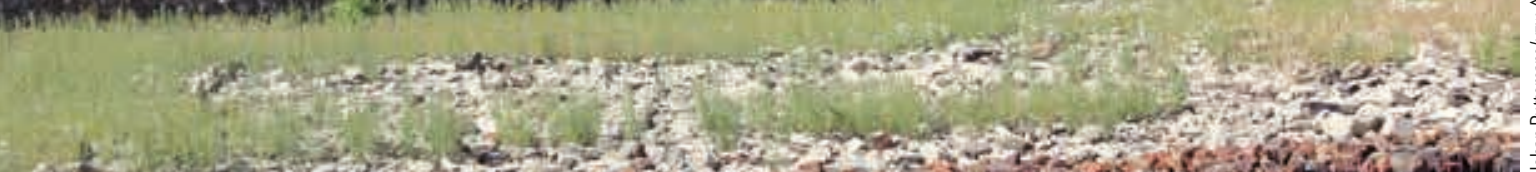



$\diamond$ De metalen structuur symboliseert de wachttoren van waaruit SS-wachters alle kamp
nauwlettend konden controleren.

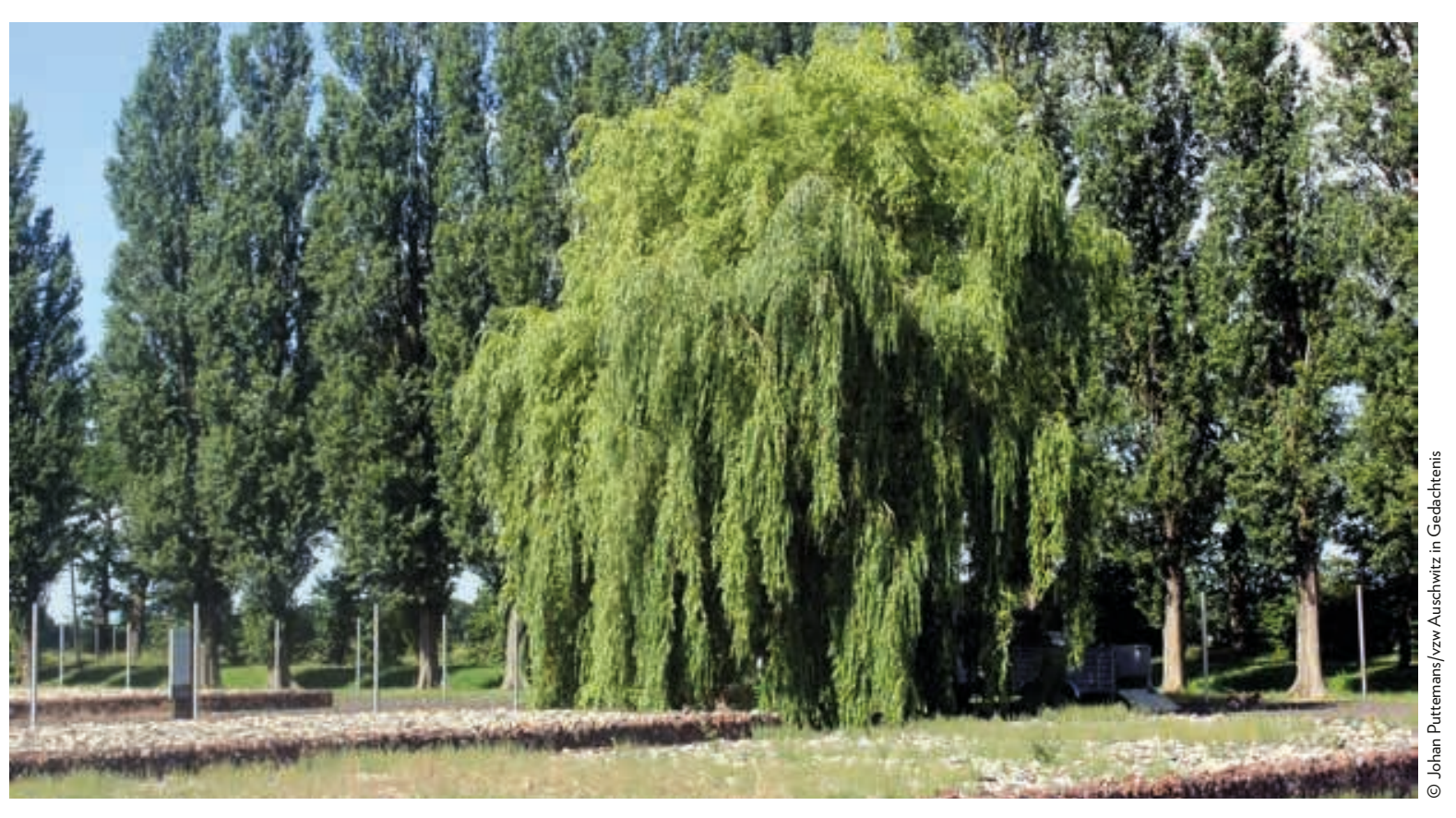

Onder deze boom, naast de barakken, hielden de S'ers een moestuin. De assen van de verbrande lichamen werd er als meststof gebruikt.
loen moestiun
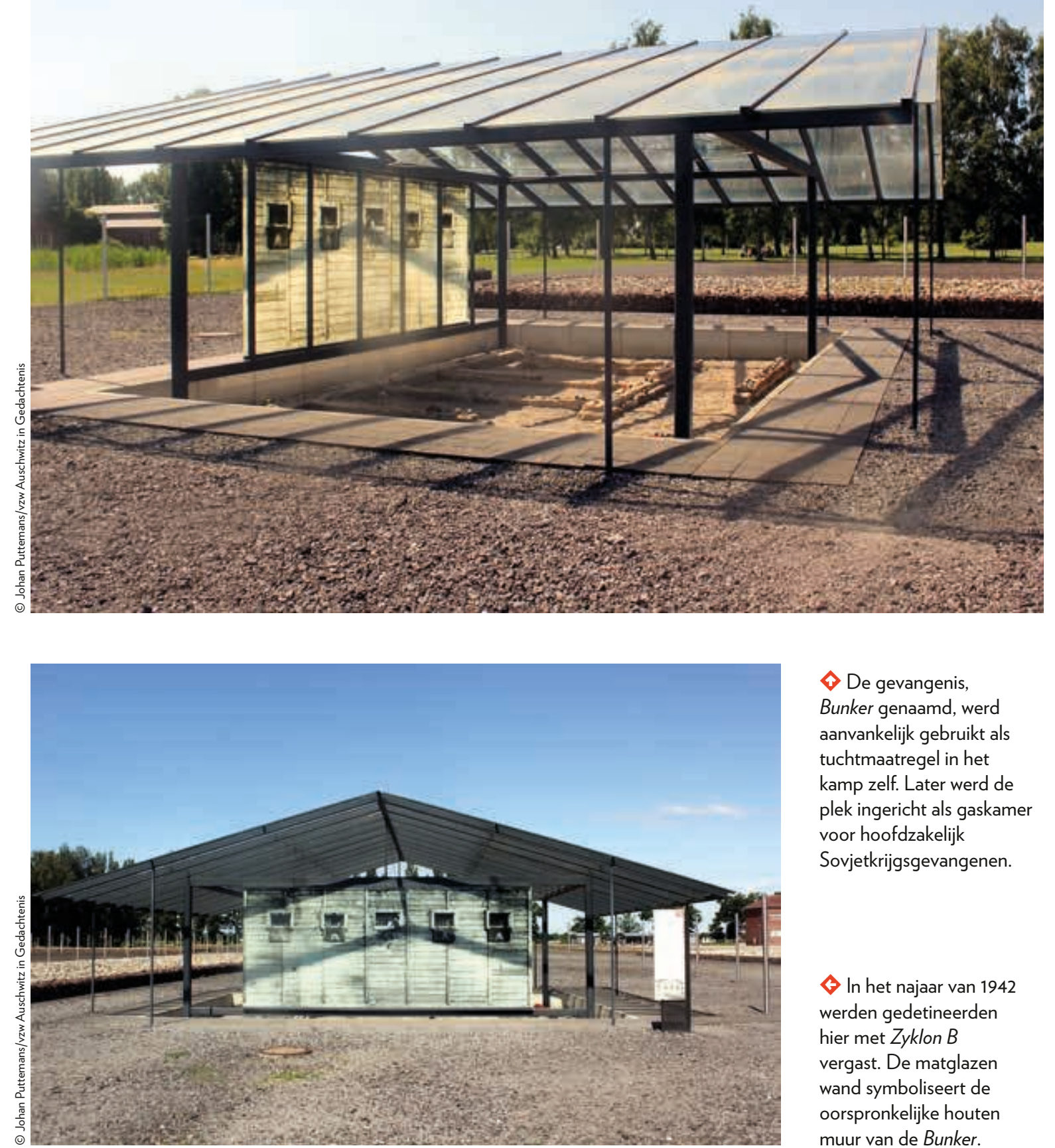

$\triangle$ De gevangenis

Bunker genaamd, werd

aanvankelijk gebruikt als

tuchtmaatregel in het

kamp zelf. Later werd de

plek ingericht als gaskamer

Sovjetkrijgsgevangenen.

$\diamond$ In het najaar van 1942

In het najaar van 1942
werden gedetineerden

werden gedetineet Zyklon $B$

hier met Zyklon B
vergast. De matglazen

wand symboliseert de

oorspronkelijke houte 


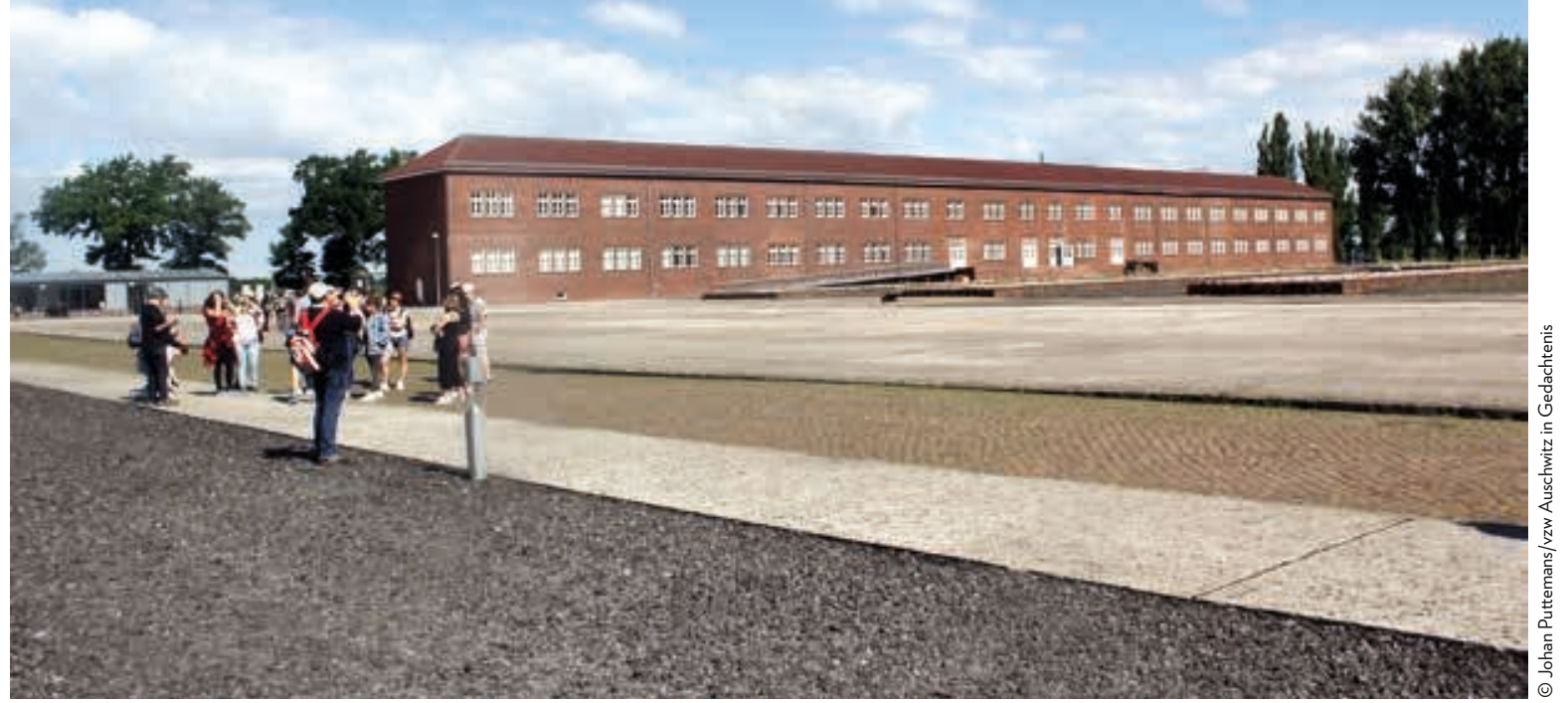

$\checkmark \mathrm{Na}$ een lange en vermoeide werkdag stonden de

kampgedetineerden soms urenlang op de Appelplatz. De

Op de Appelplatz is vandaag nog goed te zien waar
ooit de barakken stonden.

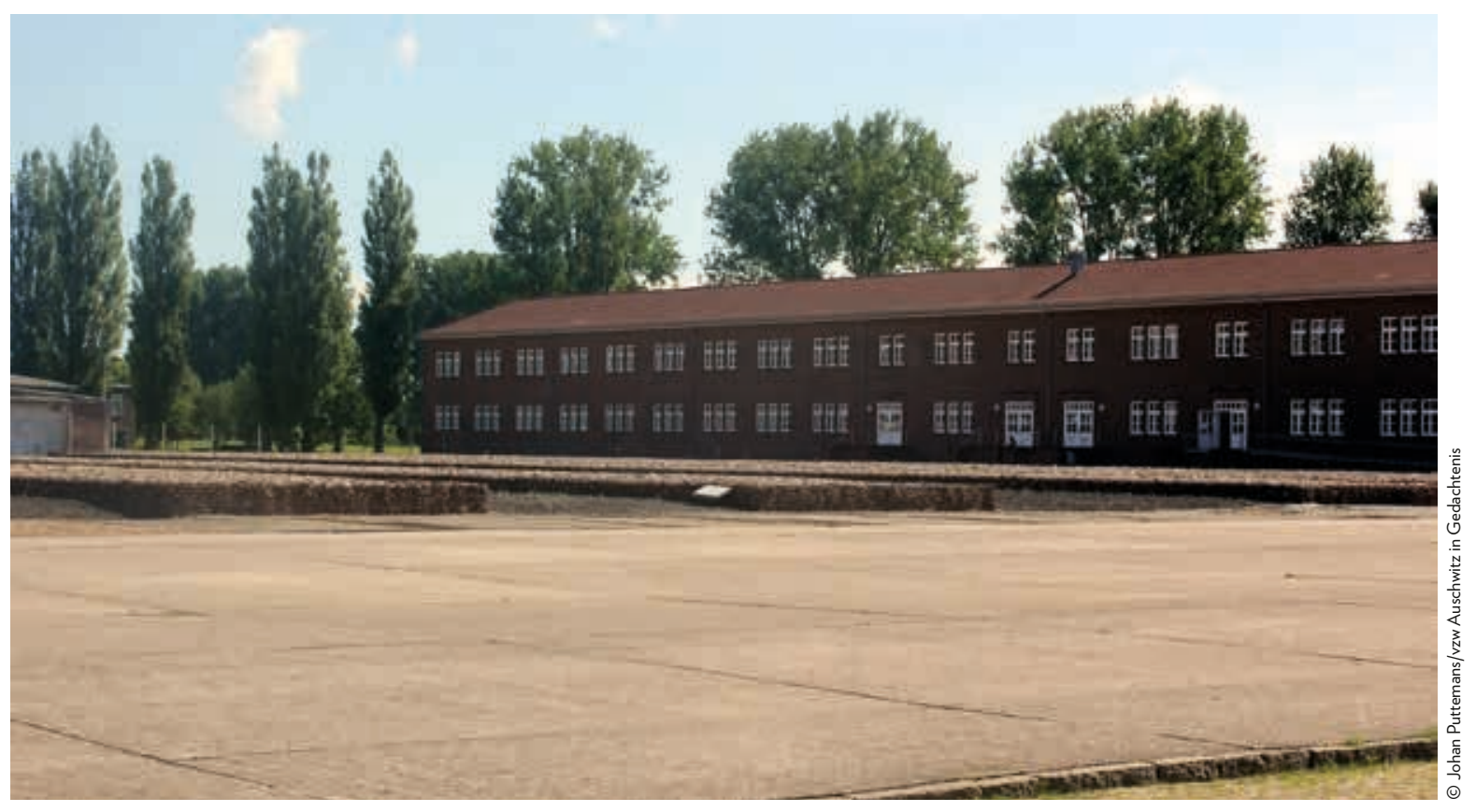

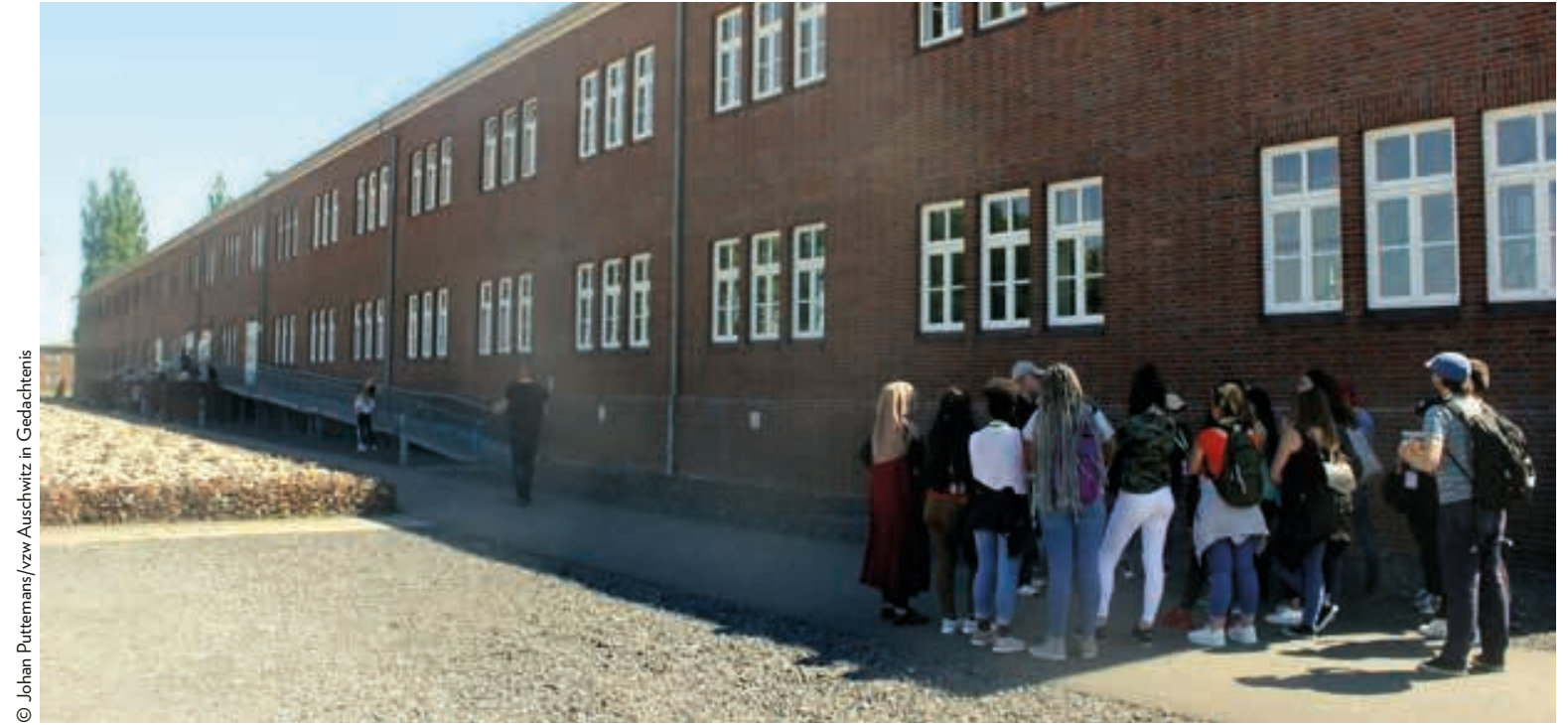

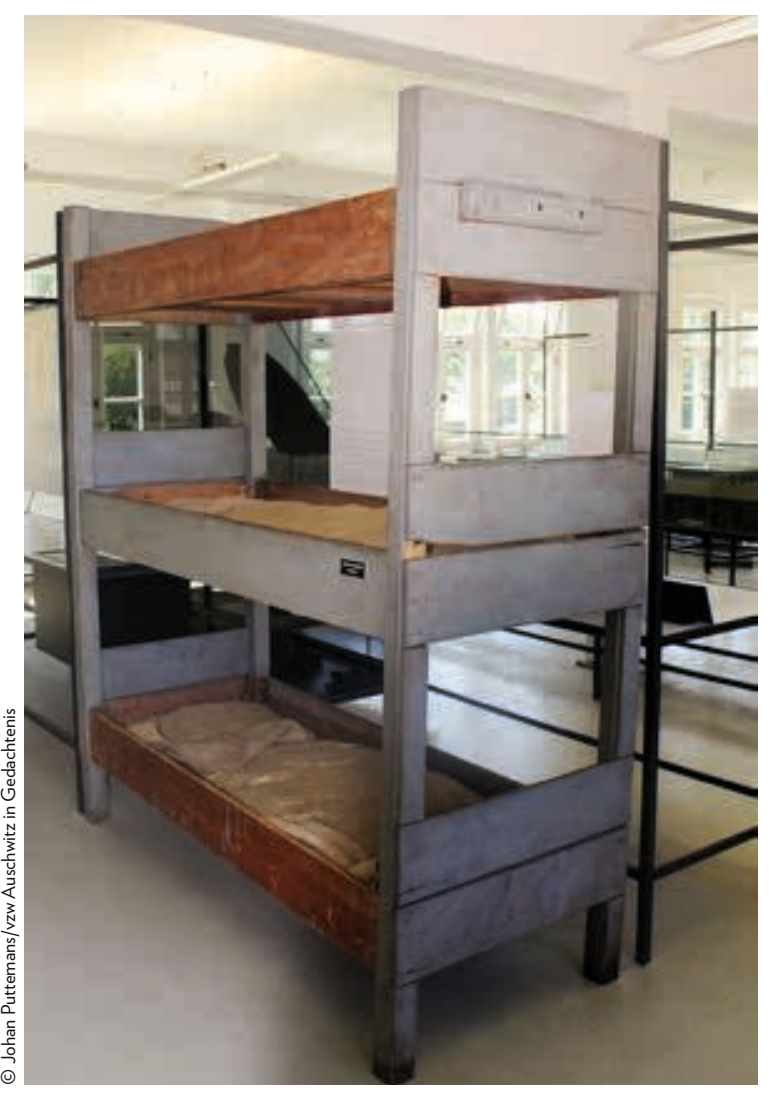

De welbekende stapelbedden,

die een goede nachtrust onmogelijk maakten.

$\diamond$ Dit type gebouw werd als Block benut. De

SS sloot er zo'n 3000

kampgedetineerden in

op. Sinds 2005 is hier de

te bezoeken. 




$\checkmark$ Deze vlakte is vandaag met gras begroeid, maar vroeger werd er klei ontgonnen. De grondstof werd me In de fabriek werden uit
de klei bakstenen gemaakt.

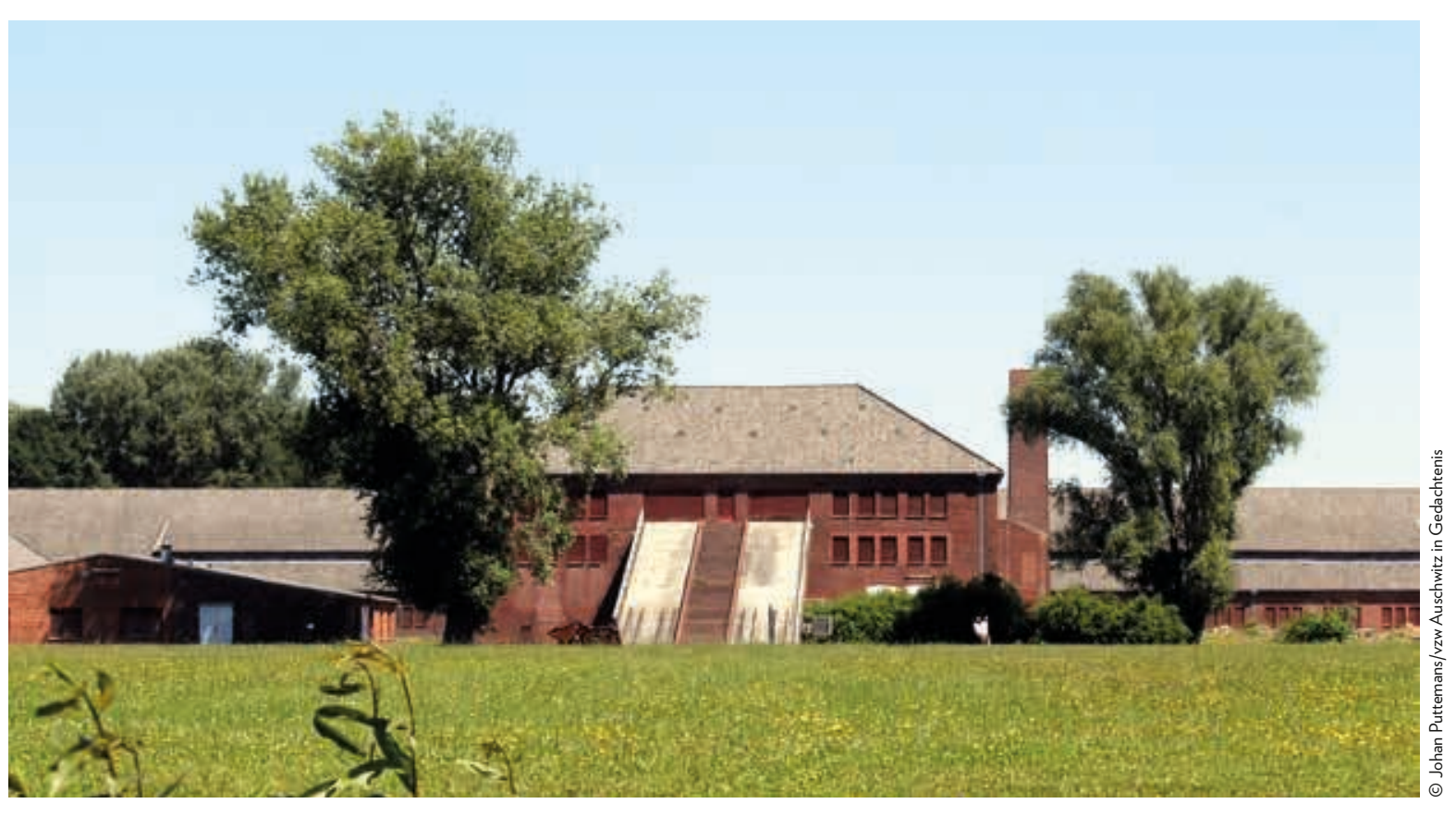

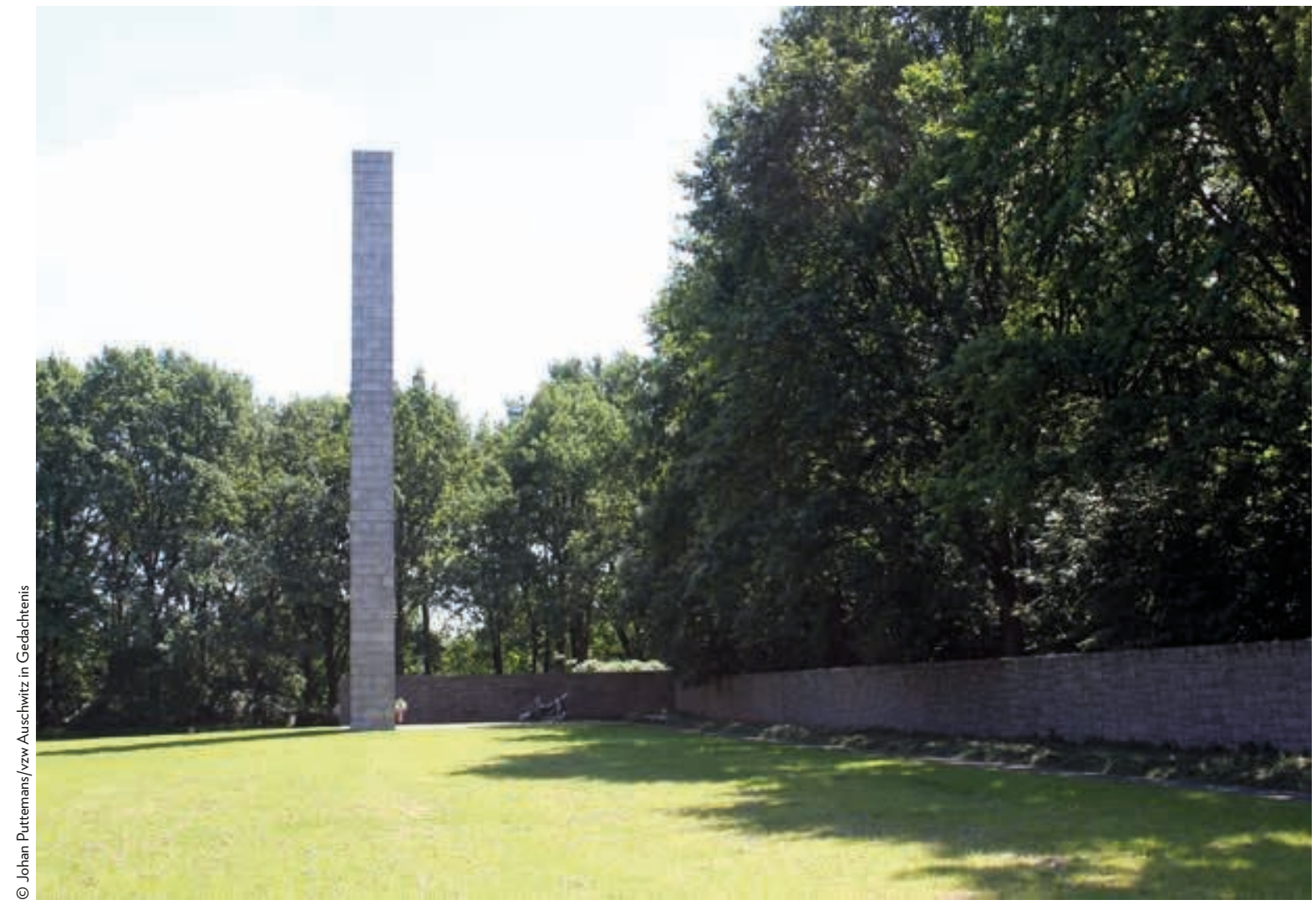

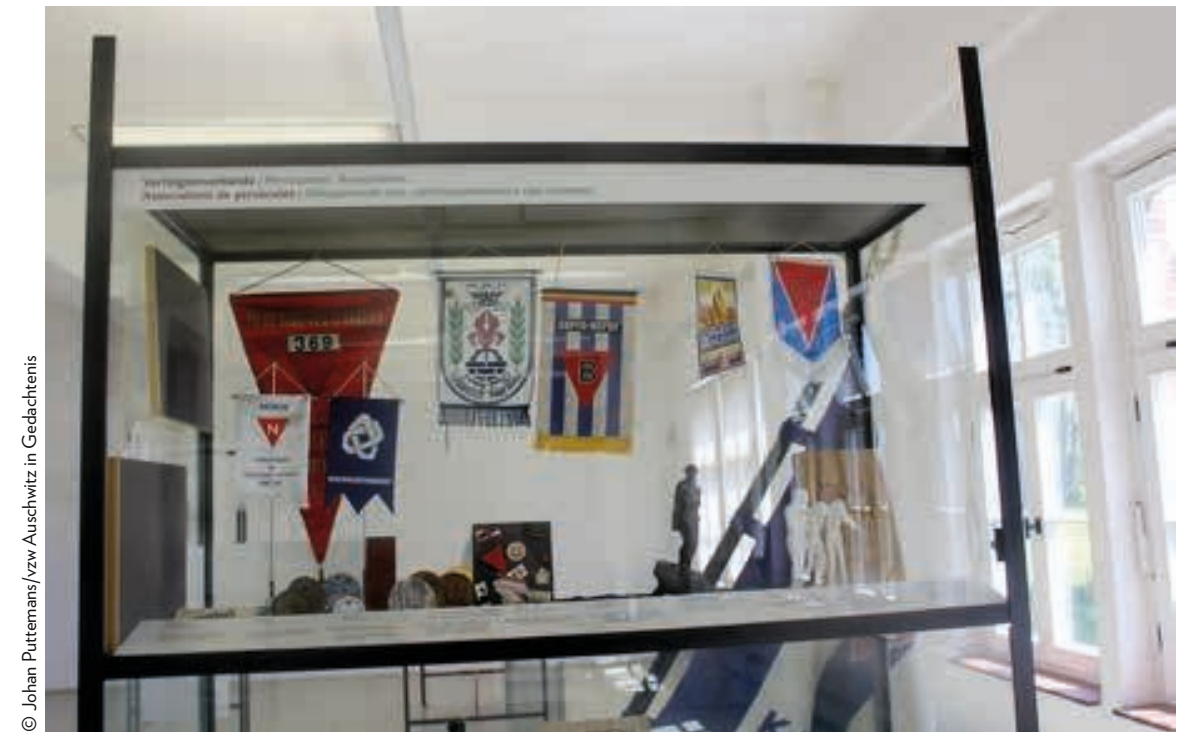

$\Delta$ Dit monument herdenk alle slachtoffers die gevallen zijn in het voormalige concentratiekamp namme.

In de glazen uitstalkast in het museum hangen vaandels van verschillende nationaliteiten, waaron die van de Nationale Confederatie van Politieke Gevangenen van België. 
Op de vier muren

staan ale namen
sande

van de gestoven
kampgedetennerden

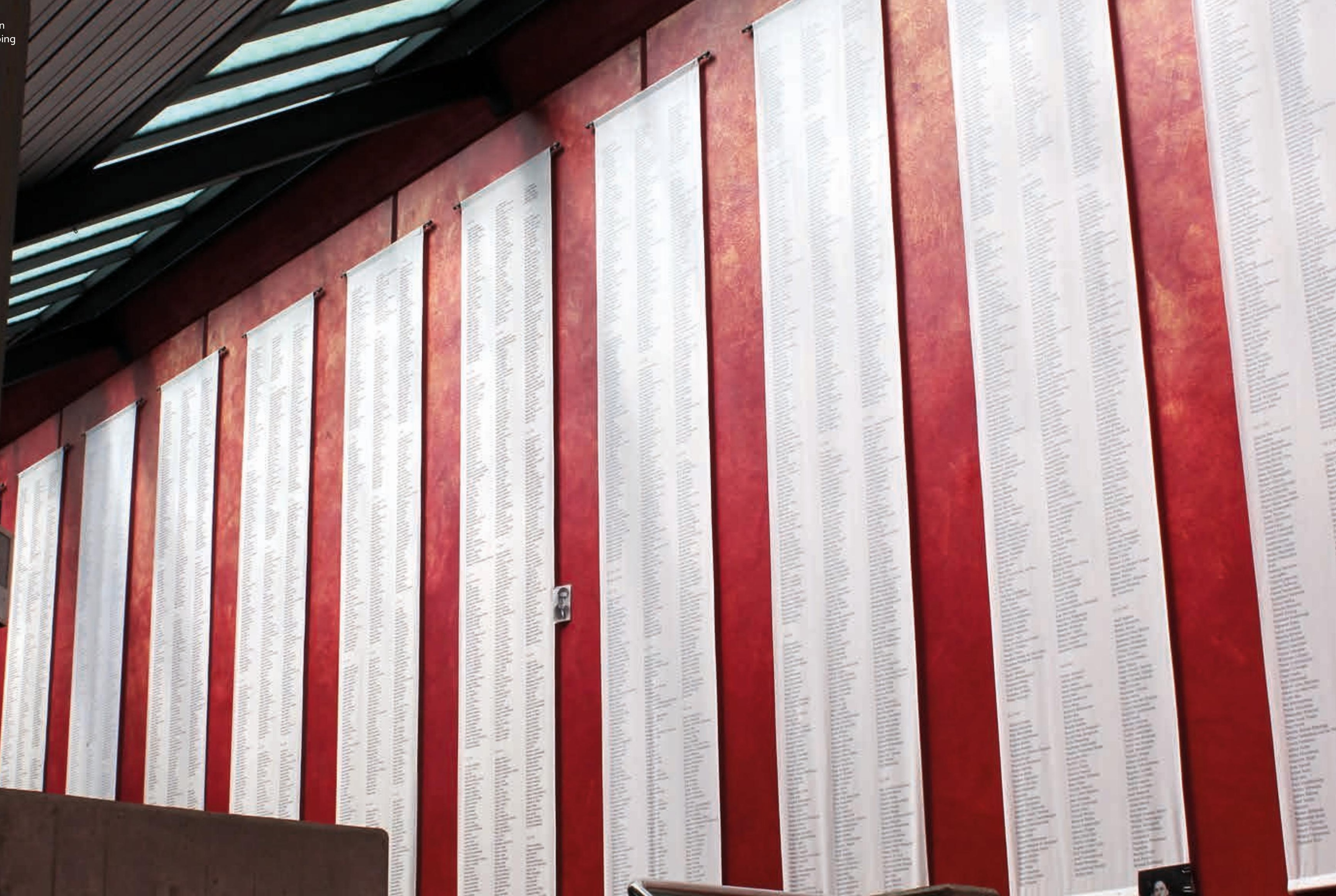

